\title{
Computer Aided Simulation of Multiple Effect Evaporator for Concentration of Caustic Soda Solution
}

Wai-Ogosu, Biriye Danwi, Kenneth K. Dagde*, Jackson G. Akpa, ThankGod Oweifa Goodhead Department of Chemical of Petrochemical Engineering, Rivers State University, Nkpolu-Oroworukwo, Port Harcourt, Nigeria

\section{Article History}

Received: 18.09.2020

Accepted: 05.10.2020

Published: 29.10 .2020

Journal homepage:

https://www.easpublisher.com/easjecs

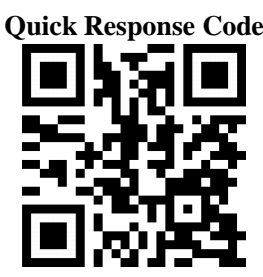

Abstract: In this work, a mathematical model has been developed for the simulation of multiple effect evaporators (MEE) system from a set of non-linear equations, Evaporation is the most energy intensive unit in pulp and paper industries, feed and product flashing, condensate, boiling point rise, vapour bleeding, etc are considered to reduce energy consumption. An inquiry into PZ PLC, a manufacturing industry situated in Aba, Abia state; for concentrating liquor using falling film plate evaporator in steam splitting in the first two effects to generate vapour used in vapour bodies within the system. Evaporation is the removal of solvent as vapour from a solution. It is the operation which is used for concentration of solution. There could be single effect evaporator or multiple effect evaporators. With addition of each effect steam economy of the system also increases. Evaporators are integral part of a number of a process industry like Pulp and Paper, Sugar, Caustic Soda, Pharmaceuticals, Desalination, Dairy and Food Processing etc. Caustic Soda Industry is of present interest. The system consists of triple effect having falling film evaporator as each effect. There is forward feed and backward feed flow. This paper describes a steady state model of multiple effect evaporators for simulation purpose. The model includes overall as well as component mass balance equations, energy balance equations and heat transfer rate equations for area calculation for all the effects. Each effect in the process is represented by a number of variables which are related by the energy and material balance equations for the feed, product and vapour flow for forward feed \& backward feed, The results of present work with concentration in effect-I at 0.853558 was validated against previous work of (Kumar and Zain, 1996) at 0.7942216 and it shows close agreement. Also considering a backward result of effect-III product $L_{3}$ as 0.327396 while that of (Kumar and Zain, 1996) as 0.398923 from the comparison with past work as well as industrial data at an inlet temperatures of $90^{\circ} \mathrm{C}$ and $76^{\circ} \mathrm{C}$ for $1^{\text {st }}$ and $2^{\text {nd }}$ effects respectively, it shows that the present model can be applied to simulate a real MEE system by improving steam economy up to 2.46 through the incorporation of flash vapours from condensate steam. The code has been developed using MATLAB 5.8B. Results of the present approach are validated with industrial data.

Keywords: Triple/Multiple Effect Evaporator, Newton Raphson Method, Caustic Soda, Matlab 5.8B, Forward/Backward Feed.

Copyright (C) 2020 The Author(s): This is an open-access article distributed under the terms of the Creative Commons Attribution 4.0 International License (CC BY-NC 4.0) which permits unrestricted use, distribution, and reproduction in any medium for non-commercial use provided the original author and source are credited.

\section{INTRODUCTION}

Evaporation is of immense importance in the process industries and is widely used for salvage solvate, food concentration, pulp and paper, soap processes, etc. The goal of evaporation is to vaporize water out of a solution containing an end product. The recovery of useful chemicals, which include sodium sulphide, sodium hydroxide and sodium carbonate from the Kraft process that uses multiple effect evaporator system as recovery process. Caustic soda $(\mathrm{NaOH})$ is commercially involved in the production of solid soap and detergents while caustic potash $(\mathrm{KOH})$ is involved in the production of liquid soap and detergents. Concentration of dilute alkali solution reduces bulk and weight for further processing. It has also been indicated that the concentration of caustic to a strength of about $50 \%$ weight fraction (commercial strength) results in precipitation impregnated salts from its solution [1]. Multiple-effect evaporators (MEE) in most industries operate in the forward-feed arrangement, in which steam and solute flow in the same direction. Advantages of this flow arrangement include the exposure of the most concentrated solute to the lowest saturated water vapor temperature in the last effect; feed flashing on entering the second and subsequent effects, which assists flow circulation, and favourable pressure profile that does not require pumping between effects. Multiple-effect evaporators were also operated in the backward-feed arrangement, in which steam and solute flow in opposite directions. It can be shown that if the 
hot and cold fluids in a counter-flow heat exchanger and a parallel-flow heat exchanger have identical inlet temperatures, the log-mean temperature difference is larger in the counter-flow heat exchanger. Since heat transfer between the hot and cold fluids is proportional to the log-mean temperature difference, the counterflow heat exchanger can transfer more heat than the parallel-flow heat exchanger that has the same heating surface area. As a result, if the inlet temperatures of the hot and cold fluids are fixed, the counter-flow heat exchanger will yield lower outlet temperature of the hot fluid and higher outlet of the cold fluid. Superior energy efficiency of the counter-current flow or backward-feed arrangement in the multiple-effect evaporators was demonstrated by Bhargawa et al. [2]. The backwardfeed arrangement is used in several industries.

There have been several investigations on the improvement of energy efficiency of the MEE system by reducing steam consumption in the evaporator [3] recommended retrofitting the evaporation process to improve heat recovery [4] performed an analysis showing that steam consumption could be reduced by increasing the number of effects. Mechanical vapour compression and thermal vapour compression have also been suggested, [5] and [4] as methods of increasing the energy efficiency of a multiple-effect evaporator. Steam consumption by a multiple-effect evaporator can also be minimized by distributing heating surface areas optimally in the process. Previous investigations by [4] have demonstrated the existence of the optimum distribution of heating surface areas that results in the minimum steam consumption. Modelling and simulation of multiple effect evaporator systems has been subject of many investigations Stewart and Beveridge, Radovic et al. [6], Newell [7], Kumar and Zain, [8], Bhargava et al. [2], Miranda et al. [9], Vazquez et al. [10], etc. Holland [11] talked about a general simulation model in an excellent monograph on fundamentals and modelling separation processes whereby a large number of non-linear equations are to be solved during simulation of a MEE system. The extent of non-linearity depends upon the number of effects and complexities of the constitutive relationships etc. Use of Newton Raphson numerical method was recommended by [11] to solve model equations, this method has been used by many researchers for the simulation of multiple effect evaporator systems [12, $13,3,2]$, and there simulation results have been reported. However, no specific study has been made about the computational aspects. During this work, we present the computational experiences in industrial scale which we encountered during the simulation of a triple effect evaporators used for concentrating the caustic soda solution. Besides, empirical correlations for the enthalpies of steam condensate and caustic soda solution have been developed. A new arrangement of model equations is also proposed to facilitate their solution. An enquiry into the caustic soda employed by a manufacturing industry, PZ, PLC in Aba, Nigeria, indicates that the caustic soda solution employed in their soap production is prepared from imported concentrated anhydrous caustic pellets, diluted to a required concentration. This is probably due to the fact there is no caustic soda concentration plant, available in the country; therefore, leading to revenue loss.

In this paper, performances of MEE systems that use the backward-feed multiple-effect evaporator and the forward-feed multiple-effect evaporator in their evaporation processes are compared. Mathematical models of both multiple-effect evaporators were developed for this purpose. It will be demonstrated by simulation that the backward-feed multiple-effect evaporator is responsible for the higher energy efficiency of the MEE system. The simulation of a caustic soda concentration plant is therefore necessary to fully comprehend the operation of a real situation of caustic concentration, using multiple effect evaporators.

\section{MATERIALS AND METHODS Model Development Development of Models for N-Forward and N- Backward Multiple Effect Evaporators}

Figure 1 and 2 shows a multiple effect evaporator system of N-Forward feed and N-Backward feed arrangement of a triple stage for the concentration of caustic soda solution. This evaporator system is depicted schematically, for $N \geq j \geq I$ system of evaporators. 


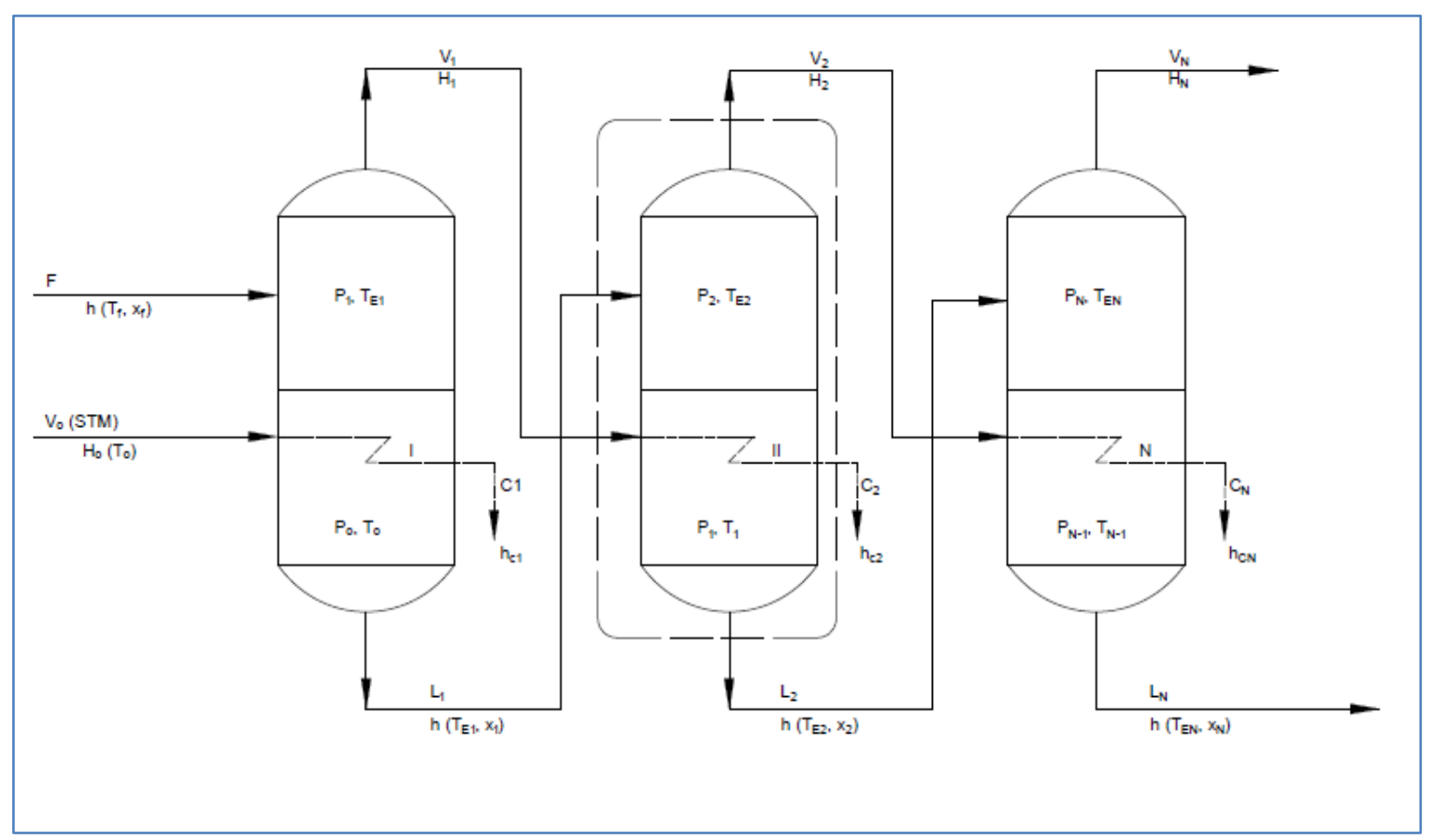

Fig-1: General N-Effect Forward feed evaporator System

where: $\mathrm{V}=$ Vapour flowrate, $\mathrm{kg} / \mathrm{hr} . \mathrm{T}=$ Saturated Temperature. $\mathrm{H}=$ Liquor Enthalpy $\mathrm{KJ} / \mathrm{kg}$, $\mathrm{F}=$ Feed flowrate, $\mathrm{Kg} / \mathrm{hr}$. $T_{E}=$ Solution Temperature, $\mathrm{L}=$ Process liquor flowrate, $\mathrm{kg} / \mathrm{hr}$.

$\mathrm{P}=$ Product. $\mathrm{C}=$ Condensate $. \mathrm{N}=$ Number of evaporator effects, $\mathrm{f}=$ feed

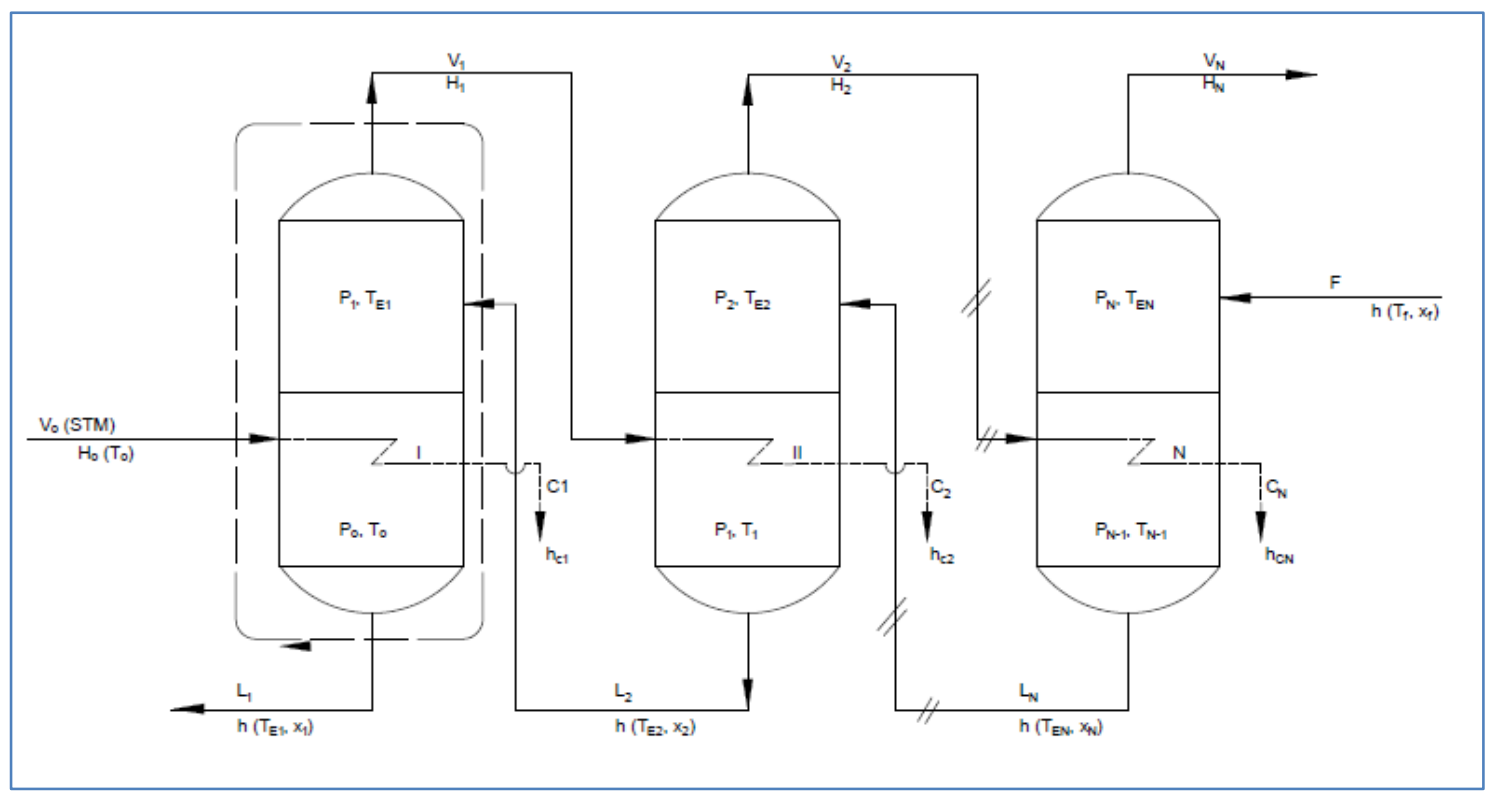

Fig-2: General N-Effect Backward feed evaporator system

\section{Model Assumption}

The general conservation equation for physical systems is defined as follows:

Input rate + Rate of generation $=$ Output rate + Rate of Accumulation - Rate of Depletion

i. Material balance on process fluid:

Applying the general conservation equation for physical systems, equation (1) in terms of mass flowrate at steady state conditions gives;

Total balance $L_{1}-V_{2}-L_{2}=0$

Liquid solute balance $=L_{1} x_{1}-L_{2} x_{2}=0$

ii. Energy Balance on Process fluid:

$$
\begin{aligned}
& L_{1} h_{1}\left(T_{E 1, x_{1}}\right)+V_{1} H_{1}\left(T_{E 1}\right)-V_{1} h_{c 2}\left(T_{1}\right)-V_{2} H_{2}\left(T_{E 2}\right)-L_{2} h_{2}\left(T_{E 2} x_{2}\right)=0 \\
& \rightarrow L_{1} h_{1}+V_{1}\left[H_{1}-h_{c 2}\right]-V_{2} H_{2-} L_{2} h_{2}=0
\end{aligned}
$$


iii. $\quad$ Enthalpy Balance on the Steam Chest:

$$
\begin{aligned}
& V_{1} H_{1}\left(T_{E 1}\right)-V_{1} h_{c 2}\left(T_{1}\right)=Q_{E 2} \\
& \text { Also, the evaporator heat duty, } Q_{E 2} \text { is given by: } \\
& Q_{E 2}=Q_{2} A_{2}\left(T_{1}-T_{E 1}\right)
\end{aligned}
$$$$
\text { Substituting equation (5)into (4)and simplifying: }
$$$$
U_{2} A_{2}\left(T_{1}-T_{E 2}\right)-V_{1}\left(H_{1}\left(T_{E 1}\right)-h_{C 2}\left(T_{1}\right)\right)=0
$$

iv. From mass equilibrium relationship, considering appreciable heat of dilution and Boiling Point Elevation effects, applying Duhring's rules (1998):

$V_{2}=L_{1}-L_{2}$

$$
\begin{aligned}
& T_{E 1}=m\left(x_{2}\right) T_{1}+b\left(x_{2}\right) \\
& \rightarrow m\left(x_{2}\right) T_{1}+b\left(x_{2}\right)-T_{E 2}=0
\end{aligned}
$$

Hence, eliminating equation (2) without losing form by substituting equations (10) \& (11) into equations (3), (4) (7) and (9) gives a compressed four models, as:

$$
\begin{aligned}
& L_{1} h_{1}\left(T_{E 1, x_{1}}\right)+\left(F-L_{1} H_{1}\left(T_{E 1}\right)-h_{c 2}\left(T_{1}\right)-\left(L_{1} L_{2}\right) H_{2}\left(T_{E 2}\right)-L_{2} h_{2}\left(T_{E 2} x_{2}\right)=0\right. \\
& U_{2} A_{2}\left(T_{1}-T_{E 2}\right)-\left(F-L_{1}\right) H_{1}\left(T_{E 1}\right)-h_{C 2}\left(T_{1}\right)=0 \\
& m\left(x_{2}\right) T_{1}+b\left(x_{2}\right)-T_{E 2}=0 \\
& L_{1} x_{1}-L_{2} x_{2}=0 \\
& L_{1}\left[h\left(T_{E 1, x_{1}}\right)-\left[h\left(T_{E 2}, x_{2}\right)+\left(F-L_{1}\right)\left[H\left(T_{E 1}\right)-h_{c}\left(T_{1}\right)\right]-\left(L_{1} L_{2}\right)\left[H\left(T_{E 2}\right)\right.\right.\right. \\
& -h\left(T_{E 2} x_{2}\right)=0
\end{aligned}
$$

This is derivable from equation (11), through algebraic manipulations as follows:

$L_{1} h_{1}+\left(F-L_{1}\left[H_{1}-h_{c 2}\right]-\left(L_{1}-L_{2}\right) H_{2}-\left(T_{E 2}\right)-L_{2} h_{2}=0\right.$

$L_{1} h_{1}+F H_{1}-L_{1} H_{1}-F h c_{2}+L_{1} h c_{2}-L_{1} H_{2}+L_{2} H_{2}-L_{2} h_{2}=0$

Modifying equation (17), without altering the equation form:

$L_{1} h_{1}+L_{1} h_{2}-L_{1} h_{2}+F H_{1}-L_{1} H_{1}-F h c_{2}+L_{1} h c_{2}-L_{1} H_{2}+L_{2} H_{2}-L_{2} h_{2}$

$L_{1}\left(h_{1}-h_{2}\right)+\left(F-L_{1}\right) H_{1}-\left(F-L_{1}\right) h_{c 2}-\left(L_{1}-L_{2}\right) H_{2}-\left(L_{1}-L_{2}\right)\left(-h_{2}\right)$

$L_{1}\left(h_{1}-h_{2}\right)+\left(F-L_{1}\right)\left[H_{1}-h_{c 2}\right]-\left(L_{1}-L_{2}\right)\left[H_{2}-h_{2}\right]$

$L_{1}\left[h\left(T_{1}, x_{1}\right)-h\left(T_{2}, x_{2}\right)\right]-\left(F-L_{1}\right)\left[H\left(T_{E 1}\right)-h_{c 2}\left(T_{1}\right)\right]-\left(L_{1}-L_{2}\right)\left[H\left(T_{E 2}\right)-h\left(T_{E 2} x_{2}\right)\right]$

\section{Forward Feed N-Effect steady state Model Equations}

\section{Effect $j=1$}

$$
\begin{aligned}
& F h_{f}\left(T_{f}, x_{f}\right)+V_{0} \lambda_{o}\left(F-L_{1}\right) H_{1}\left(T_{E 1)}-L_{1} h_{1}\left(T_{E 1,} x_{1}\right)=0\right. \\
& U_{1} A_{1}\left(T_{0}-T_{E 1}\right)-V_{0} \lambda_{o}=0 \\
& m\left(x_{1}\right) T_{1}+b\left(x_{1}\right)-T_{E 1}=0 \\
& F_{x f}-L_{1} x_{1}=0
\end{aligned}
$$

Effect $2 \leq \boldsymbol{j} \leq \boldsymbol{N}-\mathbf{1})$

$L_{j-1} h_{j-1}+\left(L_{j-2}-L_{j-1}\right)\left[H_{j-1}-h_{c j}\right]-\left(L_{j-1}-L_{j}\right) H_{j}-L_{j} h_{j}=0$

$U_{j} A_{j}\left(T_{j-1}-T_{E 1}\right)-\left(L_{j-2}-L_{j-1}\left[H_{j-1}-h_{c j}\right]=0\right.$

$m\left(x_{j}\right) T_{j}+b\left(x_{j}\right)-T_{E j}=0$

$L_{j-1} x_{j-1}-L_{j} x_{j}=0$

Effect $\boldsymbol{J}=\boldsymbol{N}$

$$
\begin{aligned}
& L_{N-1} h_{N-1}+\left(L_{N-2}-L_{N-1}\right)\left[H_{N-1}-h_{C N}\right]-\left(L_{N-1}-L_{N}\right) H_{N}-L_{N} h_{N}=0 \\
& U_{N} A_{n}\left(T_{N-1}-T_{E N}\right)-\left(L_{N-2}-L_{N-1}\left[H_{N-1}-h_{c N}\right]=0\right. \\
& m\left(x_{N}\right) T_{N}+b\left(x_{N}\right)-T_{E N}=0 \\
& L_{N-1} x_{N-1}-L_{N} x_{N}=0
\end{aligned}
$$

Effect $\mathbf{1} \leq \boldsymbol{j} \leq \boldsymbol{N}-\mathbf{1})$

$L_{j+1} h_{j+1}+\left(L_{j-2}-L_{j-1}\right)\left[H_{j-1}-h_{c j}\right]-\left(L_{j+1}-L_{j}\right) H_{j}-L_{N} h_{j}=0$

$U_{j} A_{j}\left(T_{j-1}-T_{E j}\right)-\left(L_{j}-L_{j-1}\right)\left[H_{j-1}-h_{c j}\right]=0$

$m\left(x_{j}\right) T_{j}+b\left(x_{j}\right)-T_{E j}=0$ 
$L_{j+1} x_{j+1}-L_{j} x_{j}=0$

Effect $J=N$

$L_{2} h_{2}+V_{0} \lambda_{o}-\left(L_{2}-L_{1}\right) H_{1}-L_{1} h_{1}=0$

$U_{1} A_{1}\left(T_{0}-T_{E 1}\right)-V_{0} \lambda_{o}=0$

$m\left(x_{1}\right) T_{1}+b\left(x_{1}\right)-T_{E 1}=0$

$L_{2} x_{2}-L_{1} x_{1}=0$

Forward Feed, Triple-Effect function Equations

$F 1=F h_{f}+V_{0} \lambda_{0}-\left(F-L_{1}\right) H_{1}-L_{1} h_{1}$

$F 2=U_{1} A_{1}\left(T_{0}-T_{E 1}\right)-V_{0} \lambda_{o}$

$F 3=m\left(x_{1}\right) T_{1}+b\left(x_{1}\right)-T_{E 1}$

$F 4=F_{x f}-L_{1} x_{1}$

$F 5=L_{1} h_{1}+\left(L_{0}-L_{1}\right)\left(H_{1}-h_{c 2}\right)-\left(L_{1}-L_{2}\right) H_{2}-L_{2} h_{2}$

$=\quad U_{2} A_{2}\left(T_{1}-T_{E 1}\right)-\left(L_{0}-L_{1}\right)\left[H_{1}-h_{c 2}\right]$

$F 7=m\left(x_{2}\right) T_{2}+b\left(x_{2}\right)-T_{E 2}$

$F 9=L_{2} h_{2}+\left(L_{1}-L_{2}\right)\left[H_{2}-h_{c 3}\right]-\left(L_{2}-L_{3}\right) H_{3}-L_{3} h_{3}$

$F 10=U_{3} A_{3}\left(T_{2}-T_{E 3}\right)-\left(L_{1}-L_{2}\right)\left[H_{2}-h_{c 3}\right]$

$F 11=m\left(x_{3}\right) T_{3}+b\left(x_{3}\right)-T_{E 3}$

$F 12=L_{2} x_{2}-L_{3} x_{3}$

Backward Feed, Triple-Effect function Equations

$\begin{array}{lll}F 1 & = & F h_{f}\left(L_{3}-L_{2}\right)\left[H_{2}-h_{C 3}\right]-\left(F-L_{3}\right) H_{3}-L_{3} h_{3} \\ F 2 & = & U_{3} A_{3}\left(T_{2}-T_{E 3}\right)-\left(L_{3}-L_{2}\right)\left[H_{2}-h_{c 3}\right] \\ F 3 & = & m\left(x_{3}\right) T_{3}+b\left(x_{3}\right)-T_{E 3} \\ F 4 & = & F x_{f}-L_{3} x_{3} \\ F 5 & = & L_{3} h_{3}\left(L_{2}-L_{1}\right)\left[H_{1}-h_{C 2}\right]-\left(L_{3}-L_{2}\right) H_{2}-L_{2} h_{2} \\ F 6 & = & U_{2} A_{2}\left(T_{1}-T_{E 2}\right)-\left(L_{2}-L_{1}\right)\left[H_{1}-h_{c 2}\right] \\ F 7 & = & m\left(x_{2}\right) T_{2}+b\left(x_{2}\right)-T_{E 2} \\ F 8 & = & L_{3} x_{3}-L_{2} x_{2} \\ F 9 & = & L_{2} h_{2}+V_{0} \lambda_{o}-\left(L_{2}-L_{1}\right) H_{1}-L_{1} h_{1} \\ F 10 & = & U_{1} A_{1}\left(T_{0}-T_{E 1}\right)-V_{0} \lambda_{o} \\ F 11 & = & m\left(x_{1}\right) T_{1}+b\left(x_{1}\right)-T_{E 1} \\ F 12 & = & L_{2} x_{2}-L_{1} x_{1}\end{array}$

\section{Thermodynamics Relations}

The following thermodynamic parameters pertaining caustic soda solution has been correlated:

a) Boiling point of solution (Bhargava et al., 2008)

$T_{E}=(1.0+0.0 .1419526 x) T+150.75706 x^{2}-2.7095138 x$

The variation in boiling point rise can be calculated using the following expression [2]: $\mathrm{T}=20 \mathrm{X}(0.1+x)^{2}$

where: $T_{E}=$ Solution Temperature. $\mathrm{T}=$ Saturation Temperature.

b) Overall heat transfer coefficient [14]

$U_{E}=977.66\left(T_{E} / x\right)^{0.2823}$

Error $= \pm 3.5 \%$, where: $\mathrm{x}=$ Mass fraction of solute.

c) Latent hat of vaporization of Steam [14]

$\lambda=-80.345 T-21035.87 / T+2049.23 \sqrt{ } T$

$-4213.529 \operatorname{In}(T)+0.098 T^{2}-1.04 \times 10^{-4} T^{-3}+8597.953$

Error $= \pm 85 \%$, The applicable temperature range $=32-180^{\circ} \mathrm{C}$

d) Enthalpy of saturated and superheated steam [14]

$$
\begin{aligned}
& h=-4.154 T-21035.87 / T+2049.23 \sqrt{T} \\
& -2.025 \times 10^{-4}\left(T_{E}{ }^{-2}-T^{2}\right)-0.03747 \times 10^{-7}\left(T_{E}{ }^{-2}-T^{2}\right)+\lambda
\end{aligned}
$$


Error $= \pm 1.2 \%$, The applied up to a temperature range of 0 to $100^{\circ} \mathrm{C}$

e. Enthalpy of Condensate at saturation temperature $h_{C}$, from the data obtained from steam table [15]

$h_{C}=0.103527+4.18625 T$

Error $= \pm 0.66 \%$, the applicable Validity range $=5$ to $160^{\circ} \mathrm{C}$

f. Enthalpy of caustic soda solution, from enthalpy-concentration data reported by Wilson and McCabe [15]

$h=2.59697+158.89 .896827 x+3.745764 T_{E}-2594.50984^{-2}$

$=3.758577 \times T_{E}+0.004723 T_{E}^{2}+9164.489089 x^{-3}$

$+11.005268 x^{4} T_{E}-0.002463 T_{E}^{2}-0.000031 T_{E}^{2}$

$-59333486 x^{4}-12.344381 x^{4} T_{E}-0.010289 x^{2} T_{E}{ }^{2}$

$+0.000046 x T_{E}^{3}$

Error $= \pm 2.2 \%$

\section{Solution Algorithm}

From the derivation of the set of non-linear equations of each system of model, an iterative step was followed to arrive at a set of final solution. The set of equations were inserted into a 'system of non-linear equations' along with all the constants. An initial guess of overall heat transfer coefficient $U$ was made for first iteration. Detailed algorithms for the steps are as follows to obtain the final solution:

Step 1: Values of known parameters are collected

Step 2: Assuming equal temperature difference and vaporization in each effect and liquor flow rates, an initial guess of $U$ is made to start the calculation.

Step 3: Inclusion of variations such as BPR, latent heat of vaporization, variation in specific heat of capacity, flashing (condensate, feed and product) and vapour bleeding are considered, if applicable. i.e.:

Step a: Material and energy balance around each tank is carried out.

Step b. Balanced equations derived are mainly the functions of enthalpy of vapour and condensate where the predicted values of enthalpies are used to compute

Vapour flow rates emerging from individual flash tanks. Step c: The value of vapour flow rates are added with the inlet vapour streams Entering the steam chest of Effect I to III.

Step 4: Set of non-linear equations is developed based on material and energy balance around each effect, values of $\mathrm{U}$, physical properties and flashed vapour flow rate.

Step 5: The set of equations are solved to obtain the revised values of temperatures and liquor flow rate of each effect using solver 'system of non-linear equation'. Step 6: Revised values of $U$ are computed considering temperature, flow rate and concentration of each effect. Step 7: For each effect, if differences of $U$ of two consecutive iterations fall within the range of $\pm 30 \%$ then go to step 8 . Otherwise follow step 3 to 7 with revised values of temperature, liquor flow rates and $U$. Step 8: Steam economy were computed. 


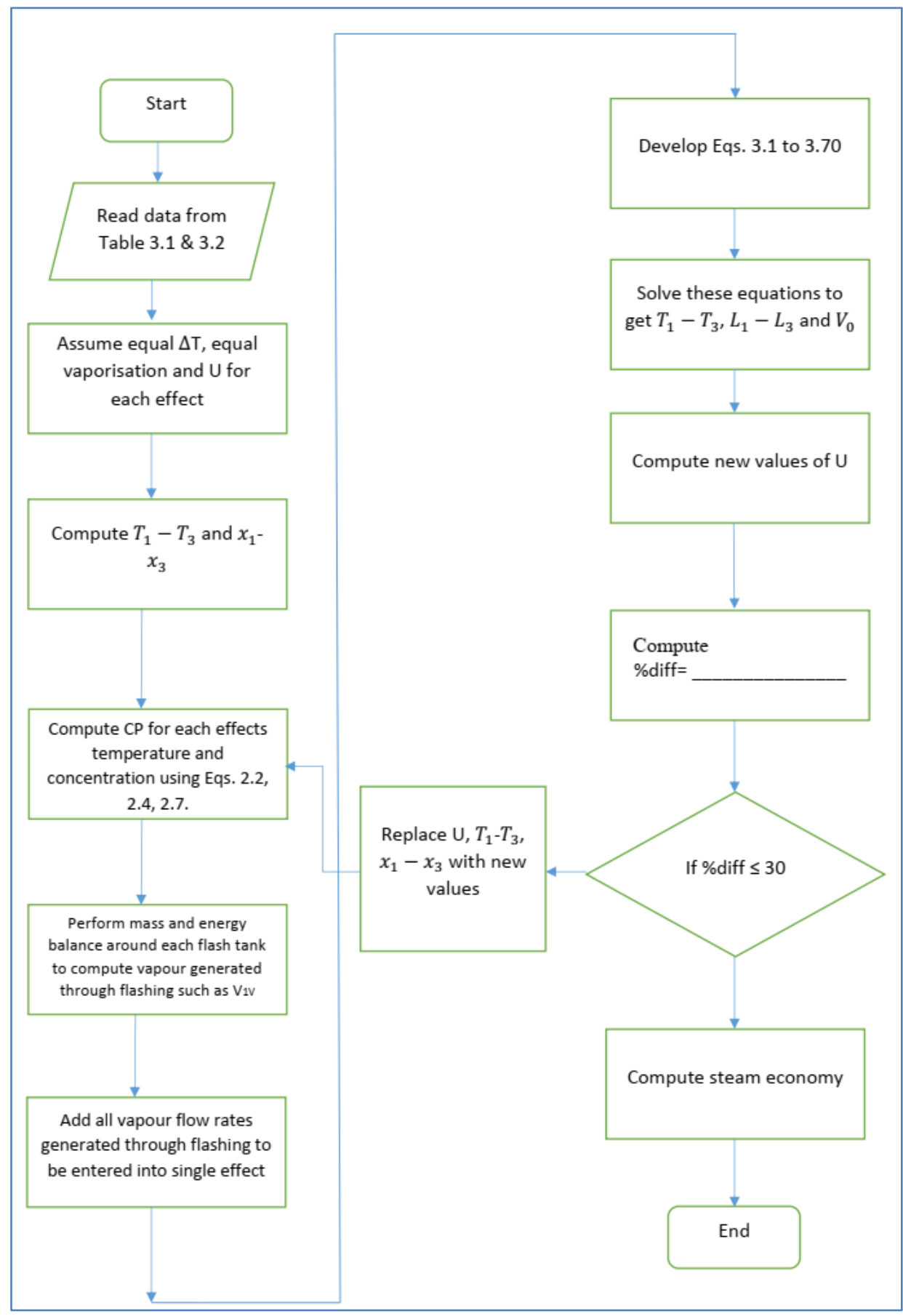

\section{Operating Parameters}

Table 1 and 2 show the input parameters from PZ industry, Operational Manual [16] for dilute caustic soda concentration to $50 \%$ weight, using triple-effect system.

Table-1: Input data for forward Feed Simulation

\begin{tabular}{|l|l|}
\hline Feed $[\mathbf{k g} / \mathbf{h})$ & $\mathbf{5 7 8 5 7 . 1 0}$ \\
\hline Feed concentration, percent weight fraction & 20.000 \\
\hline Feed Temperature Effect I \& II $\left({ }^{\circ} \mathrm{C}\right)$ & $90 \& 76$ \\
\hline Area of each effect $\left(\mathrm{m}^{2}\right)$ & 79.000 \\
\hline Input steam temperature $\left({ }^{\circ} \mathrm{C}\right)$ & 167 \\
\hline Last effect temperature $\left({ }^{\circ} \mathrm{C}\right)$ & 57,460 \\
\hline
\end{tabular}


Table-2: Input Data for Backward feed simulation

\begin{tabular}{|l|l|}
\hline Feed $[\mathbf{k g} / \mathbf{h})$ & $\mathbf{5 4 8 0 0 . 0 0}$ \\
\hline Feed concentration, percent weight fraction & 20.000 \\
\hline Feed Temperature Effect I \& II $\left({ }^{\circ} \mathrm{C}\right)$ & 90 \\
\hline Area of each effect $\left(\mathrm{m}^{2}\right)$ & 79.000 \\
\hline Input steam temperature $\left({ }^{\circ} \mathrm{C}\right)$ & 167 \\
\hline Last effect temperature $\left({ }^{\circ} \mathrm{C}\right)$ & 57 \\
\hline
\end{tabular}

Table-3: Steam Economy comparison

\begin{tabular}{|l|l|}
\hline & STM ECONOMY (E) \\
\hline Forward feed Simulation & 1.48 \\
\hline Backward Feed Simulation & 1.64 \\
\hline
\end{tabular}

\section{RESULTS AND DISCUSSION}

Table $4 \& 5$ shows the comparison between industrial plant data and predictions from the model $(3 \ldots . .3 \ldots)$, indicating that the predicted data agree reasonably well with the plant data. These results show deviations ranging from 0.05 to $19.6 \%$ for the forward feed and 0.07 to $19.5 \%$ for backward feed multiple effect evaporators respectively.

Table-4: Forward Feed Simulation Results

\begin{tabular}{|l|c|c|c|}
\hline Scaled Variable & Simulation output & PZ Plant Result & \% Deviation \\
\hline$V_{0} / F$ & 0.736262 & 0.735929 & 0.05 \\
\hline$T_{E 1} / T_{0}$ & 0.642578 & 0.643278 & 0.11 \\
\hline$T_{1} / T_{o}$ & 0.72439 & 0.722704 & 0.23 \\
\hline$X_{1}$ & 0.853558 & 0.798549 & 6.89 \\
\hline$L_{1} / F$ & 0.569049 & 0.707659 & 19.59 \\
\hline$T_{E 2} / T_{0}$ & 0.816132 & 0.813615 & 0.31 \\
\hline$T_{2} / T_{0}$ & 0.628363 & 0.622951 & 0.87 \\
\hline$X_{2}$ & 0.450186 & 0.453252 & 0.68 \\
\hline$L_{2} / F$ & 0.974931 & 0.917455 & 6.26 \\
\hline$T_{E 3} / T_{0}$ & 0.11753 & 0.129277 & 9.09 \\
\hline$X_{3}$ & 0.3 & 0.313505 & 4.31 \\
\hline$L_{3} / F$ & 0.449652 & 7.297051 & 2.46 \\
\hline
\end{tabular}

The detailed simulation results are shown in Table 4 and 5, where it shows that liquor gets much concentrated when it moves from $3^{\text {rd }}$ Effect to $1^{\text {st }}$ Effect. The rate of water evaporation in the effects is due to availability of temperature change, it also depends on the value of $U$. Table 4 shows that product $L_{1}$ is exiting the system with flow rate of $5.69049 \mathrm{~kg} / \mathrm{s}$ which corresponds to the concentration of 0.853558 . For Effect-I total steam consumption is $1.480 \mathrm{~kg} / \mathrm{s}$. 
Table-5: Backward Feed Simulation Result

\begin{tabular}{|l|c|c|c|}
\hline Scaled Variable & Simulation output & PZ Plant Result & \% Deviation \\
\hline$V_{o} / F$ & 0.61485 & 0.611521 & 0.54 \\
\hline$T_{E 1} / T_{o}$ & 1.012243 & 1.012942 & 0.07 \\
\hline$T_{1} / T_{o}$ & 1.057957 & 0.954278 & 10.86 \\
\hline$X_{1}$ & 0.402108 & 0.404229 & 0.52 \\
\hline$L_{1} / F$ & 0.571689 & 0.710299 & 19.51 \\
\hline$T_{E 2} / T_{o}$ & 0.762063 & 0.759546 & 0.33 \\
\hline$T_{2} / T_{o}$ & 0.664501 & 0.659089 & 0.82 \\
\hline$X_{2}$ & 0.307625 & 0.315884 & 2.61 \\
\hline$L_{2} / F$ & 0.840316 & 0.834568 & 0.69 \\
\hline$T_{E 3} / T_{o}$ & 0.49435 & 0.428278 & 15.43 \\
\hline$X_{3}$ & 0.592982 & 0.570667 & 3.91 \\
\hline$L_{3} / F$ & 0.327396 & 0.350659 & 6.63 \\
\hline & $\mathbf{7 . 6 4 8 0 8}$ & 7.61196 & \\
\hline
\end{tabular}

From Figure 1 and 2, the mass of solute product concentration from Effect-I of forward and backward simulation were 0.853558 and 0.402108 respectively, which showed that the product concentration was considerably less in Effect-I of backward simulation.

The reduction in steam economy when compared to Effect-I of Backward simulation was lower which was due to the effect of Overall Heat Transfer coefficient that an average value of it was reduced when fouling resistance was taking into consideration which was an obvious trend.

Condensate leaving from each effect was flashed to lower temperature to obtain vapor that would be used as heating medium in the subsequent effects along with the vapor emerging from previous effect. This can be used as energy reduction scheme to reduce energy demand

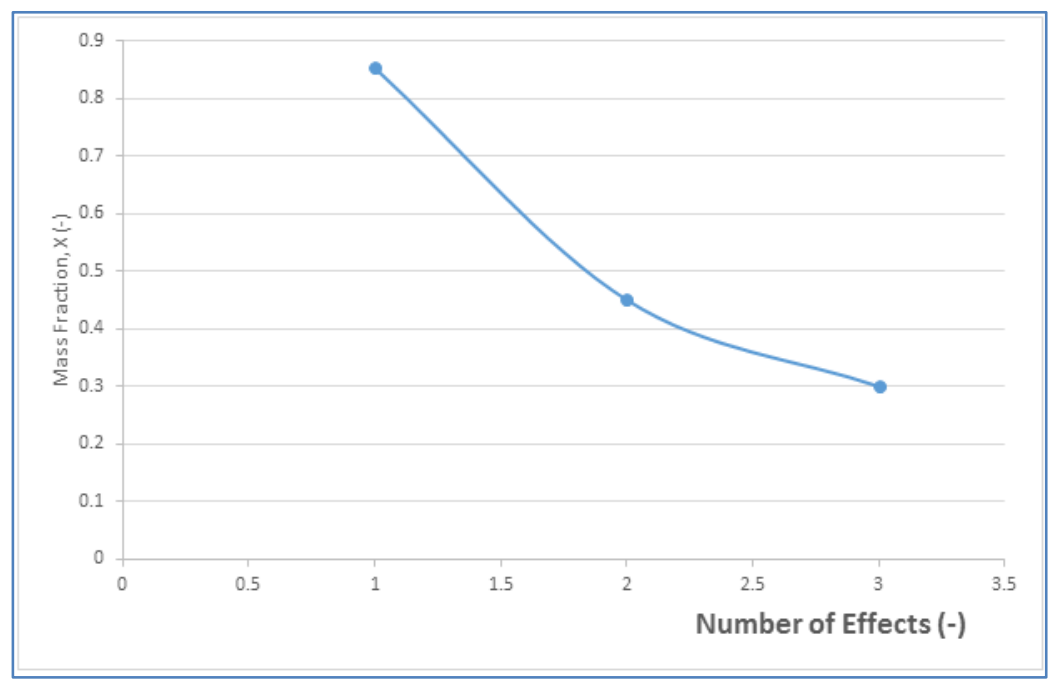

Fig-3: Variation of Mass Fraction of Caustic Soda with Number of Effects for Forward Feed Evaporators 


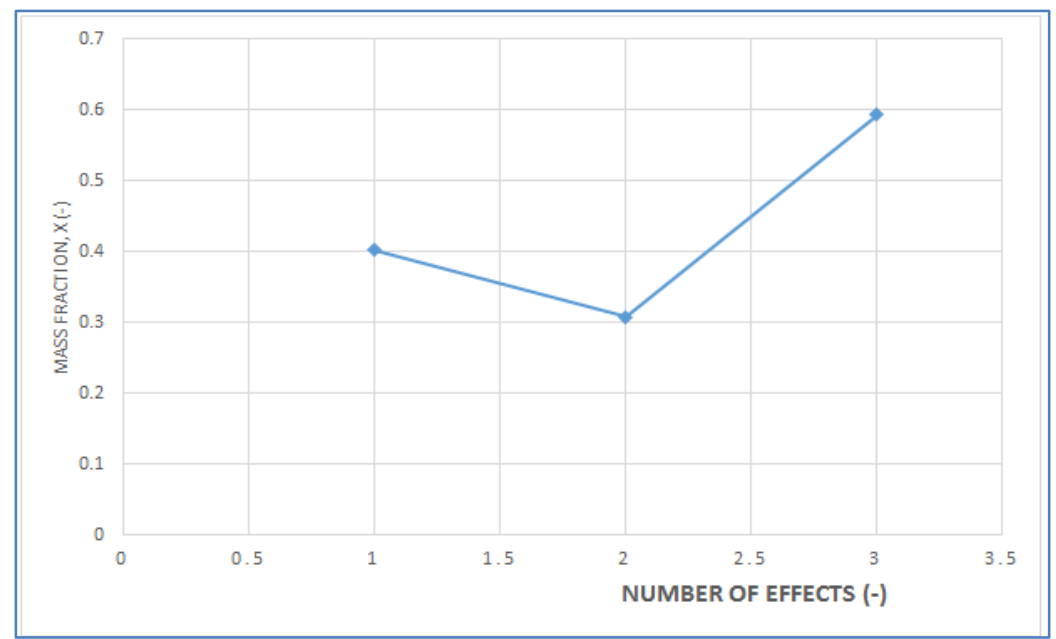

Fig-4: Variation of Mass Fraction of Caustic Soda with Number of Effects for Backward Feed Evaporators

From outside and enhance steam economy of the system. In the multiple effect evaporator system, there were 3 condensate flash tanks placed in between effects I, II and III. The condensate from each of the effect entered the respective flash tanks and the flashed vapor was used as heating medium for next effects.

Simulation results from Effect-III of both forward and backward feeds were developed considering steam splitting. Total steam was split equally in $1^{\text {st }}$ and $2^{\text {nd }}$ Effects and entered at $90^{\circ} \mathrm{C}$ and $76^{\circ} \mathrm{C}$ respectively, the rise in evaporation rate was due to larger temperature difference caused by steam splitting in the first two effects and the steam consumption was more at $1.64 \mathrm{~kg} / \mathrm{s}$, consequently steam economy for Effect-III was reduced to 2.8. Hence, introduction of steam splitting increased evaporation rate but reduced the economy of multiple effect evaporator system because for Effect-III steam was fed to the first two effects at higher temperatures of $90^{\circ} \mathrm{C}$ and $76^{\circ} \mathrm{C}$. It was a fact that as steam/vapor temperature decreased, latent heat of vaporization increased, so at higher temperature of the first two effects, Effect-III gets lesser amount of vaporization heat which caused higher steam flowrate. It can be seen from Table 3 that the rate of evaporation had increased in the $3^{\text {rd }}$ effect and decreased from Effect-I and Effect-II due to the fact that in the $3^{\text {rd }}$ effect latent heat was supplied by the vapor streams emerging from $1^{\text {st }}$ and $2^{\text {nd }}$ effects $\left(V_{1} \lambda_{1}+\right.$ $V_{2} \lambda_{2}$ ) together, however combined value of $V_{1}$ and $V_{2}$ caused more evaporation in the entire Multiple Effect Evaporator (MEE) system.

Steam is split equally in $1^{\text {st }}$ and $2^{\text {nd }}$ effects and enters these effects at $90^{\circ} \mathrm{C} \& 76^{\circ} \mathrm{C}$ as the data is used to compute liquor flow rate, this is because steam is fed to the first two effects at higher temperatures. It is a fact that as temperature of steam/vapour decreases latent heat of vaporization increases. Condensate leaving effect II is flashed to lower temperature to obtain vapour that can be used as heating medium in the subsequent effects along with the vapour emerging from previous effect, this can be used as energy reduction scheme to reduce energy demand from outside and enhance steam economy of the system.

The easiest model of the present investigation is Effect-I, which is derived based on boundary conditions, the solution of this model is varied with known values of $U$ and area.

\section{CONCLUSION}

The main objective of this paper is to demonstrate that the backward-feed multiple-effect evaporator is more energy efficient than the conventional forward-feed multiple-effect evaporator that has the same total heating surface area and process the same amount of solute. Mathematical models were developed for both evaporators for this investigation. Comparison was made between multiple effect evaporator systems that use the forward-feed and backward-feed multiple-effect evaporators. Both evaporators had the optimum distributions of heating surface areas that yielded the maximum inlet caustic soda solution flow rates. Since each system consumed the same amount of fuel, and produced the same amount of product, the energy efficiency parameter was the power output.

Hence from Table 3 steam economy comparison, the forward feed simulation is more ideal for hot feed condition. But for practical feed condition of dilute caustic soda stored at room temperature, the backward feed simulation finds more relevance in this respect leading to better steam economy and also cost saving in feed preheating for use in forward feed.

Computational aspects associated with the numerical solution of model equations of multiple effect evaporator system by Newton Raphson method have been studied. It has been found that the computation should be done using double precision arithmetic in order to obtain the converged solution. In the process, empirical correlations for the enthalpy of steam condensate and caustic soda solution have also 
been developed. A new arrangement of model equations is taking into consideration whereby the number of model equations can be reduced from 12 to 5 , which possesses a number of distinct merits over the previous one and can be applied to other multiple effect evaporator systems. Therefore, the backward-feed multiple effect evaporators were responsible for more energy efficiency in this MEE system compared with the Forward-Feed Multiple Effect Evaporator systems.

\section{REFERENCES}

1. Standiford, T. J., \& Huffnagle, G. B. (1997). Cytokines in host defense against pneumonia. Journal of investigative medicine: the official publication of the American Federation for Clinical Research, 45(6), 335.

2. Bhargava, R., Khanam, S., Mohanty, B., \& Ray, A. K. (2008). Simulation of flash falling film evaporator system for concentration of Black liquor, computes and Chemical Engineering 32, 3213-3223.43

3. Urbaniec, K., Zalewski, P., \& Zhu, X. X. (2000). A decomposition approach for retrofit design of energy systems in the sugar industry. Applied thermal engineering, 20(15-16), 1431-1442.

4. Chen, T., \& Ruan, Q. (2009). Modelling and Energy reduction of Multiple Effect Evaporator System with Thermal Vapour Compression. Comp. Chem. Eng., 515-522

5. Palacios-Bereche, R., Ensinas, A., Modesto, M., \& Nebra, S. A. (2014). New alternatives for the fermentation process in the ethanol production from sugarcane: Extractive and low temperature fermentation. Energy, 70, 595-604.

6. Radovic, L., Tasic, A., Grozdanic, D., Djordjevic, B. D., \& Valent, V. J. (1979). Computer design and analysis of operation of a multiple-effect evaporator system in the sugar industry. Industrial \& Engineering Chemistry Process Design and Development, 18(2), 318-323.

7. Newell, A. (1980). Physical symbol systems. Cognitive science, 4(2), 135-183.

8. Kumar, S. \& Zain, O. S. (1996). Simulation of Multiple Effect Evaporators for concentrating caustic soda solution-computational aspects, chem. Eng. J. of Japan, 29(5), 889-893.

9. Miranda, V., \& Simpson, R. (2005). Modeling and simulation of an industrial multiple effect evaporator: Tomato concentrate, Journal of food Engineering 66, 92, 203-210.

10. Vazquez-Rojas, R. A., Garfias-Vazquez, F. J. Bazua-Rueda E. R. Simulation of Tripple Effect Evaporator of a solution of caustic soda, Sodium chloride and Sodium Sulfate using Aspen plus. Comp. Chem. Eng. 2018, 112, 265-273

11. Holland, J. H., \& Miller, J. H. (1991). Artificial adaptive agents in economic theory. The American Economic Review, 81(2), 365-370.
12. Ghosh, P., \& Lamb, F. K. (1979). Accretion by rotating magnetic neutron stars. III-Accretion torques and period changes in pulsating X-ray sources. The Astrophysical Journal, 234, 296-316.

13. Veeramani, K. (1979). Periyar and his Ideologies. Periyar Self-respect Propaganda Institution, Chennai.

14. Agawal, V. K. (1992). Energy Conservation in Multiple Effect Evaporators, Ph.D Thesis, University of Roorkee, Roorkee, India

15. Kumar, D.V., \& Singh, V. (2010). To study the parametric effects on optimality of various feeding sequences of multiple effect evaporation in paper industry using mathematical modeling and simulation with MAICAAB, word Academy of science, Engineering and Technology 72, 114-121.

16. PZ Industry PLC, Aba. Abia State. (2010). Nigeria, Operational Manual.

\section{NOTATIONS}

\begin{tabular}{|c|c|c|}
\hline IN & $=$ & Input Term \\
\hline GEN & $=$ & Generation term \\
\hline Out & $=$ & Output term \\
\hline $\mathrm{ACC}$ & $=$ & Accumulation term \\
\hline DEPL & $=$ & Depletion Term \\
\hline Q & $=$ & Heat Term, kJ \\
\hline $\mathrm{W}$ & $=$ & Work Term, kJ \\
\hline$\lambda$ & $=$ & Latent heat of steam, $\mathrm{kJ} / \mathrm{kg}$ \\
\hline $\mathrm{U}$ & $=$ & Overall heat transfer coefficient, \\
\hline \multicolumn{3}{|c|}{$\mathrm{W} / \mathrm{m} 2{ }^{\mathrm{O}} \mathrm{C}$} \\
\hline \multicolumn{3}{|r|}{ Solution Temperature, ${ }^{\mathrm{O}} \mathrm{C}$} \\
\hline & & relaxation parameter \\
\hline $\mathrm{T}$ & $=$ & Saturation temperature, ${ }^{\mathrm{O}} \mathrm{C}$ \\
\hline$x$ & $=$ & Mass fraction of caustic soda \\
\hline \multicolumn{3}{|c|}{ solution } \\
\hline $\mathrm{H}$ & $=$ & Vapour enthalpy, kj/kg \\
\hline $\mathrm{H}$ & $=$ & Liquid Enthalpy, $\mathrm{kJ} / \mathrm{kg}$ \\
\hline $\mathrm{F}$ & $=$ & Feed flow rate, $\mathrm{kg} / \mathrm{hr}$ \\
\hline $\mathrm{L}$ & $=$ & Process liquor flowrate, $\mathrm{kg} / \mathrm{hr}$ \\
\hline A & $=$ & Heat transfer area, $\mathrm{m}^{2}$ \\
\hline$\Delta t$ & $=$ & Temperature Drop, ${ }^{\mathrm{O}} \mathrm{C}$ \\
\hline $\mathrm{Z}$ & $=$ & Evaporator cost per unit heating \\
\hline \multicolumn{3}{|c|}{ surface are } \\
\hline $\mathrm{P}$ & $=$ & Pressure, $\mathrm{kPa}$ \\
\hline $\mathrm{X}$ & $=$ & Variable \\
\hline V & $=$ & Vapour flowrate, $\mathrm{kj} / \mathrm{hr}$ \\
\hline $\mathrm{Hj}$ & $=$ & Vapour enthalpy of effect $\mathrm{j}$, \\
\hline \multicolumn{3}{|l|}{$\mathrm{kJ} / \mathrm{kg}$} \\
\hline $\mathrm{BPE}$ & $=$ & Boiling Point Elevation, ${ }^{\mathrm{O}} \mathrm{C}$ \\
\hline \multicolumn{3}{|c|}{ Subscripts } \\
\hline $\mathrm{N}$ & $=$ & Number of evaporator effects \\
\hline 0 & $=$ & Steam stream to effect 1 \\
\hline $\mathrm{E}$ & $=$ & Evaporator effect \\
\hline $\mathrm{P}$ & $=$ & Product \\
\hline$f \mathrm{f}$ & $=$ & feed function \\
\hline $\mathrm{J}=1^{0}, \mathrm{~N}$ & $=$ & Evaporator effect number \\
\hline Av & $=$ & Average \\
\hline $\mathrm{C}$ & $=$ & Condensate \\
\hline $\mathrm{t}$ & $=$ & Total \\
\hline
\end{tabular}

